\title{
Data Analysis and Result Computation (DARC) Algorithm for Tertiary Institutions
}

\author{
${ }^{1}$ Abel U. Osagie, ${ }^{2}$ Abu Mallam \\ ${ }^{1,2}$ Department of Physics, University of Abuja, Abuja, Nigeria
}

\begin{abstract}
Tertiary institutions (e.g., Universities, Polytechnics and Colleges of Education) are expected to manage and preserve data of both present and past students. These data include general information about students as well as examination results at any or all stages of studentship. Analysis of student data can be used to inform solutions to a wide variety of educational challenges like exploring group differences, gender representation, ethnic representation, and growth over time. However, data management and examination result computation of large population of students can be rigorous time-consuming and prone to errors. Information management technology offers a comprehensive portfolio of students' academic record to be available in real-time to students and professionals. That a comprehensive solution for use in many tertiary institutions is not yet common presents a unique opportunity for researchers to help shape the future of this technology. We introduce a Fortran algorithm for Data Analysis and Result Computation (DARC). The algorithm analyzes student data as well as computes examination results of all students in a department at once. DARC reads particular spreadsheet formats of students' information data, semester scores and previous academic records, after which it outputs, among others, analysis of students information, comprehensive result format for students showing grade point averages(GPA) and updated cumulative grade point averages (CGPA), summary of academic records including log of carry over courses, log of carry over courses that have been cleared, log of outstanding courses and log of outstanding courses that have been cleared. Using synthetic record of some students, we validate the reliability of the algorithm by conducting accuracy tests. The algorithm is flexible and can be suitably modified to manage and preserve academic and general records of both present and past students in any tertiary institution.
\end{abstract}

Keywords: Fortran Algorithm, Student records, Result Computation and Analysis, Reliable.

\section{Introduction}

Management and preservation of student data is one of the basic responsibilities of tertiary institutions. Research on school improvement and school effectiveness has shown data use to be central to the school improvement process (Chrispeels, 1992; Earl \& Katz, 2002). Analysis of student data can be used to inform solutions to a wide variety of educational challenges in tertiary institutions. General information about students like name, registration number, date of birth, sex, nationality, state of origin, religion, etc., as well as examination results for each and all semesters are expected to be properly calculated and preserved. However, laborious processes are usually required to compute error-free students' examination results. More so, these routines which are carried out every semester put the individuals responsible for the processes in a continuous and ever demanding cycle. Delays in the release of examination results and complaints from students about mistakes in their results are common. It is not unfair to say that some tertiary institutions still compute examination results manually; a process that is more time-consuming and error-prone. Comprehensive semester result format that can be given to students and their parents, which shows the student's information, scores, grades, process of arriving at the calculated GPA (grade point average) and CGPA (cumulative grade point averages) are uncommon. Statistics over a period of time about students such as gender and age representation in a department or faculty are usually not readily available. Existing programs are therefore inadequate in addressing some of these problems. This challenge informed the desire to develop an algorithm that will accurately compute students' results while giving important statistics about student population and their academic performances.

An algorithm can be defined as a sequence of steps that can solve a problem while a programming language provides the means of getting a computer to solve a problem (Chivers \& Sleightholme, 2006). There is a wide range of programming languages, with particular languages being suited to a particular class of problems. In this work, the computational algorithm is written in Fortran programming language. Fortran stands for formula translation and it is commonly used to solve arithmetic and scientific problems. Fortran offers essentially all of the tools recommended for object-oriented programming techniques (Ed Akin, 2001). The F90 standards committee brought into the language most of the best features of other more recent languages like Ada, C, C++, Eiffel, etc. (Ed Akin, 2001). Though any grading system can be employed, we use the Five-Point Grading System, established by the Nigerian Universities Commission (NUC) in 1989 in the student 
examination result computation section of the algorithm. The rest of the article gave a review of some related work, discusses data preparation, computation and analysis of the computed results. We finally explore the potentials available for the foreseeable future in the conclusion and recommendations section.

\section{Literature Review}

Data analysis begins with proper inventory and preparation of the data. Beyond vertical accountability, data are most useful in educational decision-making and for improvement purposes (Earl and Katz, 2002). Feldman and Tung (2001) observed that schools involved in data use often evolved toward a more professional culture. Proper information management can facilitate decision-making and improve educational standards in tertiary institutions.

Most Programming Languages can be written to analyze student data and compute examination results. More so, programming packages and database management system can be used to develop result processing software. Many examination result computation software have been developed for use in schools and colleges. Recently introduced is the Intelligent Knowledge-Based System (IKBS) built using various programming facilities in Microsoft Excel spreadsheet program (Ekpenyong, 2008). In IKBS, cell referencing tracks students' performances in hard coded Excel cells. Ukem et al, (2012) in his report pointed out that the program appears to be restrictive and requires substantial programming abilities. The reported work by Ukem et al, (2011), uses a combination of MYSQL Server, Adobe Dreamweaver and Personal Home Page Pre-Processor. The database tables and data are created with the use of MYSQL Server, the codes and Graphical User Interface are created with the use of Adobe Dreamweaver, while communication and manipulation of the database is by the help of Personal Home Page Pre-Processor (PHP). Ukem et al, (2012) however, reported that the application has not enjoyed wide usage and threw his weight behind room for improvement. A similar work was done by Emmanuel et al, (2012) for application in Nigerian Colleges of Education.

However, a comprehensive solution for both student data analysis and cumulative examination result computation for widespread use in tertiary institutions is not readily available. This provides a unique opportunity for researchers to help shape the future of this technology. Fortran continues to be an important programming language that richly rewards the effort of learning to take advantage of its power, clarity, and user friendliness (Ed Akin, 2001).

\section{i. Data Preparation}

\section{Data Preparation and Computation}

Before any meaningful computational analysis can be achieved, proper data and inventory must be taken. A list of all students with information such as name, registration number, date of birth, sex, nationality, state of origin, religion, etc., of each student in a department should be created. We save all spreadsheet as data '.dat' files and manipulated all input data files with UltraEdit or any other text editing program. Starting from the earliest session or from a particular session, we update the file with records of subsequent sessions. A section of the student information spreadsheet may look like figure 1. In the figure, there are 864 students in the department represented in the first line of the file sheet. Any other useful information may be included in the first line. Information about the students is simply added to the list in subsequent academic sessions, and the new total number of students is updated. Then, we create a spreadsheet of all possible courses that can be registered in a department. Figure 2 shows a section of a sample of such spreadsheet. After examinations are concluded, we prepare a standard spreadsheet format of the raw examination scores which are recorded against appropriate courses for all students. Here, the individuals handing the computation manually key in students' score beneath a row of all courses that can be registered in that semester. Depending on the availability of results, the spreadsheet can be for a particular academic session, a range of academic sessions or for all students in a department.

\begin{tabular}{|c|c|c|c|c|c|c|c|}
\hline 864 & NAME & SEX & DOB & STATE & LG & RELIGION & MARITAL STATUS $---\rightarrow$ \\
\hline 05284001 & BABAT Jane Yam & $\mathrm{F}$ & 01/01/80 & Kaduna & Zango & Christianity & single \\
\hline $\begin{array}{c}05284002 \\
1 \\
v\end{array}$ & ISA Joe Emeka & M & $02 / 02 / 83$ & Abia & Isik & Islam & single \\
\hline 05284143 & ABDUL Mariam J. & $\mathrm{F}$ & 20/12/82 & Kogi & Omala & Islam & married \\
\hline $\begin{array}{c}06284001 \\
\dot{v}\end{array}$ & OSAGIE Sam A. & M & $10 / 03 / 87$ & Edo & Oredo & Christianity & single \\
\hline
\end{tabular}

Figure 1: A sample format of students' general information. DOB(date of birth), LG(Local government of origin), $\mathrm{F}($ female), M(male). 


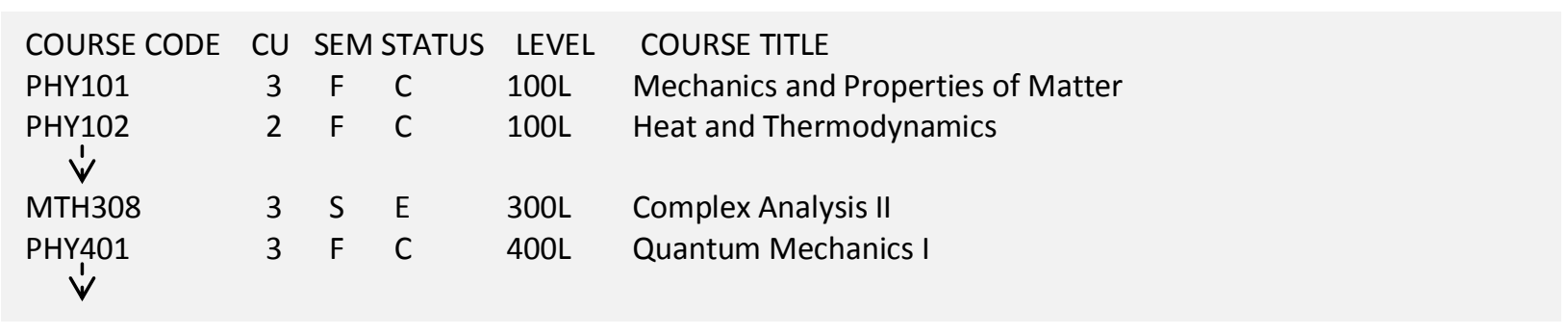

Figure 2: A sample format of course content. CU(credit unit), SEM(semester), F(first semester), S(second semester), C(core course), E(elective course)

\section{ii. Computation}

It is important that algorithms for analyzing student data are reliable, error-free and with the flexibility to accommodate future needs. The algorithm we call DARC (Data and Result Computation) satisfies these conditions. After preparing the appropriate data, we run DARC to analyze student information data, compute semester examination results, and statistics of student results. DARC mainly use student registration number as the unique identification, i.e., the computational and selective process of the algorithm employs the uniqueness of a student's registration number. The input files for DARC include:

a) Student information spreadsheet as shown in figure 1, which includes information of all students in a department.

b) All courses that can be registered in a department which include the course codes, credit units, course titles, etc., as illustrated in figure 2 .

c) Raw examination scores of all students in the department as shown in figure 3. Examination score sheets can be for a particular level or for all levels of students in the department provided their scores are placed beneath the appropriate course codes.

d) Summary file of previous results of all students.

e) Log file of previous carry over courses.

f) Log file of previous carry over courses that have been passed

g) Log file of previous outstanding courses.

h) Log file of previous outstanding courses that have been passed.

It is assumed that computation will start from a reference academic session. At the beginning stage, (d) (h) are simply a list of registration numbers of students in the reference academic session. With files (a)-(h) ready, DARC outputs among other, the following:

i. A classification of students original information data file into the various academic sessions. The file shows gender and ethnic representation in a session. If required, the file can also give statistics about age-group representation and religious demography. It also gives the above statistics for the overall student population in the department

ii. For all students, a comprehensive result format which shows all courses registered for the semester, the raw scores obtained and their respective letter grades, how the grade point average (GPA) and cumulative grade point average (CGPA) is calculated, if any, a list of carry over courses and outstanding courses for that particular semester.

iii. Result summary for all students showing previous totals of credit units registered, credit units earned. Also shown is up-to-date totals registered and earned of credit units.

iv. Log. of previous, current and cumulative carry over courses.

v. Log of previous, current and cumulative outstanding courses.

vi. $\quad$ Log of carry over courses previously and currently passed.

vii. Log of outstanding courses previously and currently passed.

viii. Statistics of class of degree for all sessions. 


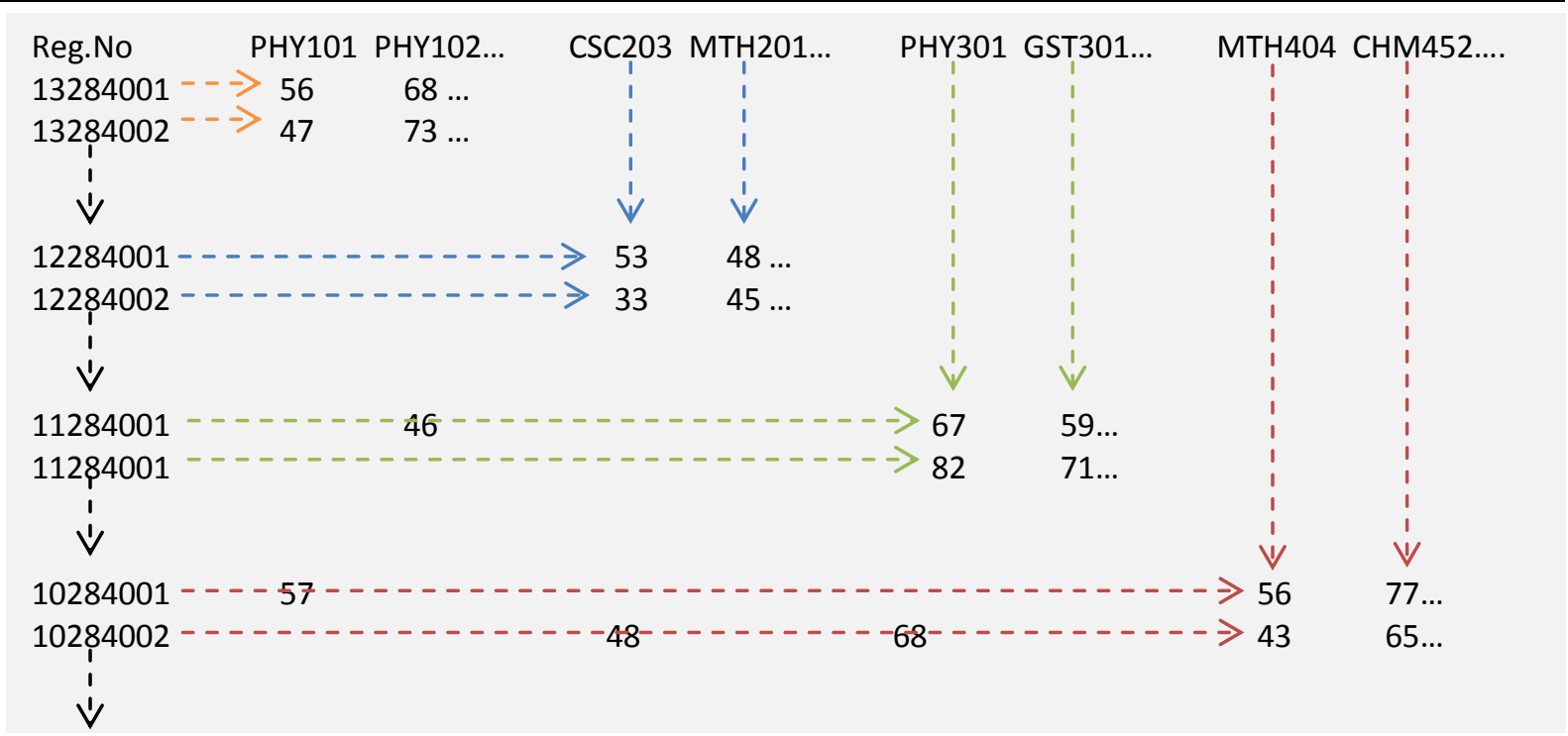

Figure 3: An example of raw examination score sheet for various academic sessions in a department with students' registration numbers and their semester scores beneath course codes

\section{Result and Analysis}

We perform accuracy test for DARC using synthetic record of some students in the department of Physics, University of Abuja, Nigeria. Using 2007/2008 as the reference session we validate the reliability of the algorithm. As an example, figure 4 shows a breakdown of student population with gender representation over a five-year period between 2007/2008 and 2011/2012, while figure 5 shows a similar distribution for one session. From the original data sheet of figure 1, DARC separates the total numbers of students into academic sessions while it gives the population and gender representation for each session. An example of a semester result output to be given to students is shown in figure 7. Among what is shown in the result sheet include some information about the student, number of courses registered for the semester, raw examination scores as well as their respective letter grades, credit points, and how the GPA for the semester is calculated. Other information include the carry over courses for the semester (if any), outstanding courses for the semester (if any), previous credit units registered, previous credit points earned, and an update of the student's CGPA. A legend for the various shorthand letters is given below for each student's result. The class of degree of students in each session is also computed in DARC as shown in figure 6. Some other output files include: a summary of academic records including log of carry over courses, log of carry over courses that have been cleared, log of outstanding courses and $\log$ of outstanding courses that have been cleared.

\begin{tabular}{|c|c|c|c|c|}
\hline \multicolumn{5}{|c|}{ Total number of students since 20} \\
\hline M (Males) & & $=537$ & & \\
\hline $\mathrm{F}$ (Females) & & $=134$ & & \\
\hline $2007 / 2008$ & 64 & & $M=47$ & $F=17$ \\
\hline $2008 / 2009$ & 96 & & $M=78$ & $F=18$ \\
\hline $2009 / 2010$ & 139 & & $M=115$ & $F=24$ \\
\hline $2010 / 2011$ & 205 & & $M=158$ & $F=47$ \\
\hline $2011 / 2012$ & 168 & & $M=139$ & $F=28$ \\
\hline Abia & & $=23$ & $M=20$ & $F=3$ \\
\hline Adamawa & & $=10$ & $M=7$ & $F=3$ \\
\hline Akwa-lbom & & $=17$ & $M=15$ & $F=2$ \\
\hline Anambra & & $=34$ & $M=22$ & $F=12$ \\
\hline Bauchi & & $=7$ & $M=7$ & $F=0$ \\
\hline Bayelsa & & $=2$ & $M=2$ & $F=0$ \\
\hline$\downarrow$ & & $\downarrow$ & $\downarrow$ & - \\
\hline
\end{tabular}

Figure 4: Demographic gender representation of students between 2007/2008 and 20011/2012 sessions 


\begin{tabular}{|c|c|c|c|}
\hline $2007 / 2008$ & session & & \\
\hline M (Males) & $=47$ & & \\
\hline F (Females) & $=17$ & & \\
\hline Total & $=64$ & & \\
\hline Abia & $=2$ & $M=2$ & $F=0$ \\
\hline Adamawa & $=1$ & $M=1$ & $F=0$ \\
\hline Akwa-lbom & $=0$ & $M=0$ & $F=0$ \\
\hline Anambra & $=3$ & $M=0$ & $F=3$ \\
\hline Bauchi & $=0$ & $M=0$ & $F=0$ \\
\hline Bayelsa & $=0$ & $M=0$ & $F=0$ \\
\hline Benue & $=3$ & $M=2$ & $F=1$ \\
\hline Borno & $=1$ & $M=0$ & $F=1$ \\
\hline Cross River & $=3$ & $M=3$ & $F=0$ \\
\hline $\begin{array}{c}\text { Delta } \\
1 \\
1 \\
\vdots \\
\mathbf{v}\end{array}$ & $\begin{array}{c}=3 \\
\vdots \\
\vdots \\
v\end{array}$ & $\begin{array}{c}M=1 \\
\vdots \\
\vdots\end{array}$ & $\begin{array}{c}F=2 \\
1 \\
1 \\
W\end{array}$ \\
\hline
\end{tabular}

Figure 5: Demographic gender representation of students for only 2007/2008 session

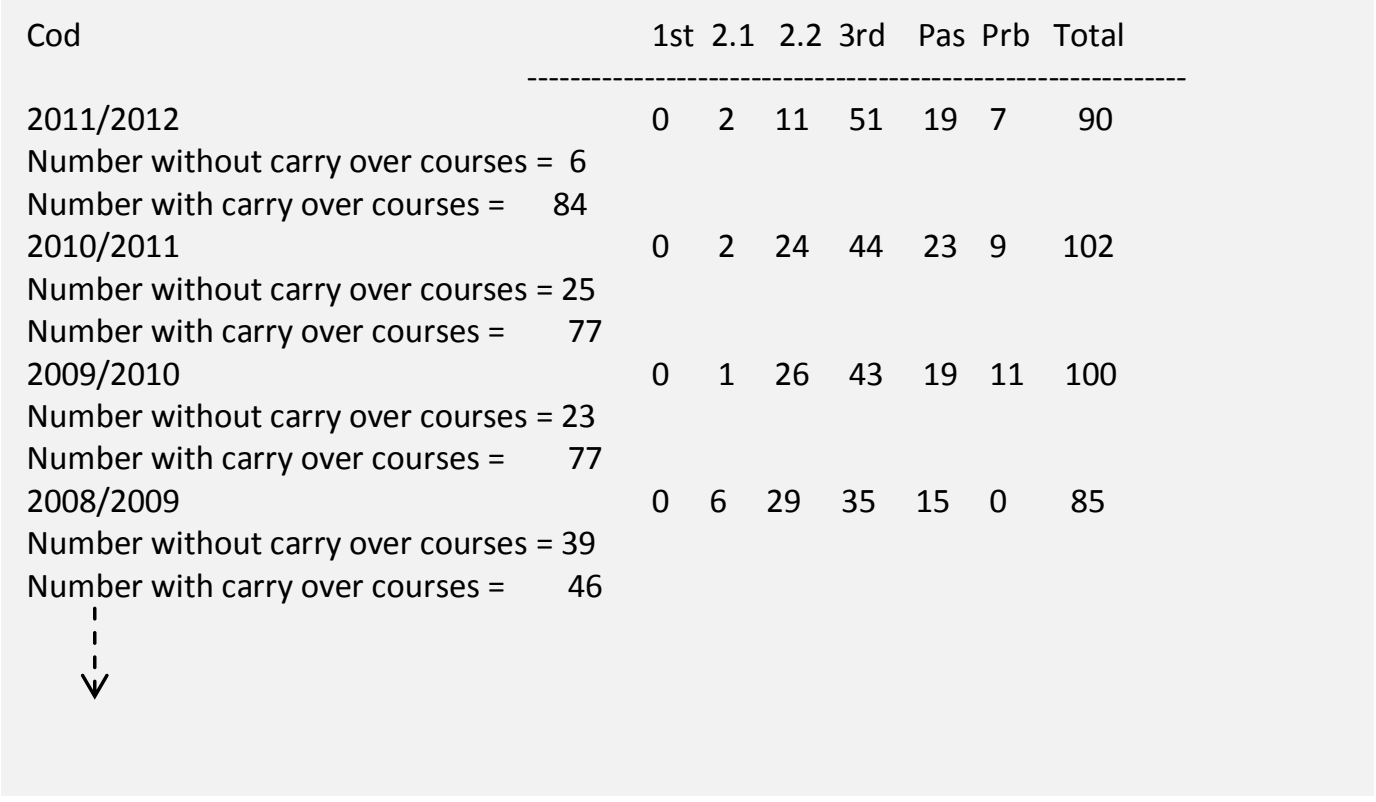

Figure 6: A sample showing Class of degree (Cod) for some academic sessions. $1^{\text {st }}$ (first class), 2.1(second class upper division), 2.2(second class lower division), Pas(pass), Prb(probation). 


\begin{tabular}{|c|c|c|c|c|c|}
\hline \multicolumn{6}{|c|}{ DEPARTMENT OF PHYSICS } \\
\hline \multicolumn{6}{|c|}{ UNIVERSITY OF ABUJA } \\
\hline \multicolumn{4}{|c|}{ OSAGIE Abel U. } & \multicolumn{2}{|c|}{ Male Sc } \\
\hline \multicolumn{6}{|c|}{ Reg. No: 09284054} \\
\hline \multicolumn{6}{|c|}{ No. of courses registered $=10$} \\
\hline code & $\mathrm{CU}$ & Sc & $\mathrm{CP}$ & Grd & $\mathrm{TCP}$ \\
\hline PHY103 & 3 & 55 & 3 & $\mathrm{C}$ & 9.0 \\
\hline PHY104 & 2 & 40 & 1 & $E$ & 2.0 \\
\hline MTH104 & 2 & 40 & 1 & $E$ & 2.0 \\
\hline GST102 & 2 & 50 & 3 & C & 6.0 \\
\hline PHY201 & 3 & 61 & 4 & B & 12.0 \\
\hline PHY208 & 1 & 54 & 3 & C & 3.0 \\
\hline CSC203 & 3 & 22 & 0 & $\mathrm{~F}$ & 0.0 \\
\hline MTH201 & 3 & 35 & 0 & $\mathrm{~F}$ & 0.0 \\
\hline MTH205 & 3 & 45 & 2 & D & 6.0 \\
\hline \multirow[t]{2}{*}{ STA101 } & 2 & 40 & 1 & $E$ & 2.0 \\
\hline & -- & & & & -- \\
\hline \multirow[t]{2}{*}{ TUR= } & 24 & TUE= & & & 42.0 \\
\hline & 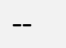 & & & & \\
\hline
\end{tabular}

This semester GPA: 42/24 = 1.75

This semester carry over courses $=2$

CSC203 FC 200L

MTH201 FC 200L

This semester outstanding courses $=2$

MTH201 FC 200L

GST203 FC 200L

Previous: $\quad$ TUR $=36 \quad$ TUE $=27 \quad \mathrm{TCP}=89$

Current CGPA $(89+42) /(36+24)=2.18$

$\mathrm{CU}=$ credit unit

Sc $=$ score

$\mathrm{Grd}=$ grade

$\mathrm{CP}=$ credit point

$\mathrm{TCP}=$ total credit point

$\mathrm{FC}=1$ st semester core

$\mathrm{SC}=2$ nd semester core

$\mathrm{FE}=1$ st semester elective

$\mathrm{SE}=2$ nd semester elective

TUR $=$ total number of units registered

TUE = total number of units earned

ANY ALTERATION INVALIDATES THIS RESULT

Figure 7: An example of a student's semester result sheet showing raw scores for courses registered, their respective letter grades, GPA for the semester, the current CGPA, list of carryover and outstanding courses (if any).

\section{Conclusion and Recommendations}

Beyond accountability, proper data management can promote data-informed decisions toward a more professional culture in tertiary institutions. It is therefore important to encourage data use. The algorithm presented in this study introduces enhancement in student data analysis by creating a range of multilevel aggregated data available to inform decision-making in tertiary institutions. The algorithm also indicates a 
significant improvement in student examination result computation and analysis. With proper file naming system, years of students' academic work can be stored electronically and meticulously archived. This can form a solid foundation of well archived students' record for future integrated systems and easy retrieval of any required information for data-informed decisions. The algorithm passed the accuracy and validity tests. Results obtained are as expected and supports all of the required objectives. This indicates that the algorithm is reliable. The algorithm is flexible and can be suitably modified to manage and preserve academic and general records of both present and past students in any tertiary institution.

However, before the implementation of the algorithm, the following are recommended:

a) For student's information data sheet, standard format for electronic data entry must be established. This can be achieved by training departmental secretaries and other relevant personnel.

b) Proper file naming system (FNS) must be adhered to by all secretaries and their successors. This will facilitate easy access to any required file by any authorized person.

c) Course lecturers should have a standard format of entering students' raw examination scores.

d) For student's result computations, effort should be made to validate the input data. The personnel handing examination results computation should be given initial orientation on how to prepare the input data files and naming the output files to conform to the proper file naming system.

\section{References}

[1]. American Association of School Administrators (2002). "Using data to improve schools: What's working". Available: www.aasa.org/cas/UsingDataToImproveSchools.pdf.

[2]. Chrispeels, J.H. (1992). "Purposeful restructuring: Creating a climate of learning and achievement in elementary schools." Lo ndon: Falmer Press.

[3]. Ed, Akin. (2001). “Object oriented programming via fortran 90/95”, Rice University, Houston, Texas

[4]. Emmanuel, B. \& Choji, D. N. "A software application for colleges of education result processing", Journal of Information Engineering and Applications, Volume 2, No. 11 (2012).

[5]. Feldman, J., \& Tung, R. (2001). "Using data based inquiry and decision-making to improve instruction", ERS Spectrum 19(3), 1019.

[6]. Fullan, M.G., \& Miles, M.M. (1992). "Getting reform right: What works and what doesn't”, Phi Delta Kappan, 73 (10), $744-752$.

[7]. Ian D. Chivers \& Jane Sleightholme, (2006), "Introduction to programming with fortran”, Springer-Verlag London Limited.

[8]. Moses E. Ekpenyong.(2008). “A Real-Time IKBS for students results computation”, International Journal of Physical Sciences (Ultra Scientist of Physical Sciences) Volume 20, Number 3(M), September - December, 2008. Available: http://www.mySQL.com, (July 22,2012)

[9]. Okonigene, R.E., Ighalo, G.I., Ogbeifun, E. (2008). "Developed personal record software", The Pacific Journal of Science and Technology .9(2):407-412. Available: http://www.akamaiuniversity.us/PJST.htm (July 15,2012).

[10]. Stringfield, S., Wayman, J.C., \& Yakimowski, M. (2003, March). "Scaling up data use in classrooms, schools, and districts", Paper presented at the Scaling Up Success conference, Harvard Graduate School of Education, Boston MA.

[11]. Ukem, E et al. (2012). "A software application for university students results processing", Journal of Theoretical and Applied Information Technology, Vol. 35 No.1. Available: www.jatit.org, (July 2,2012).

[12]. Ukem , E. O. and Onoyom-Ita, E. O. (2011). "A software application for the processing of students results", Global Journal of Pure and Applied Sciences Volume 17 No. 4. Available: http://en.wikipedia.org/wiki/PHP, July 22/7/2012.

[13]. Wayman, J.C., Stringfield, S., \& Yakimowski, M. (2004, January). "Software enabling school improvement through analysis of student data", Center for Research on the Education of Students Placed At Risk (CRESPAR), U.S. Department of Education. 